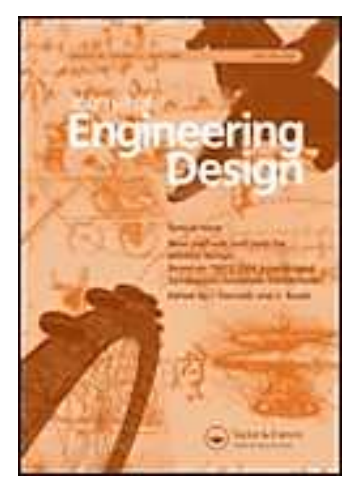

\title{
An investigation into usability and exclusivity issues of digital programmable thermostats
}

\begin{tabular}{|r|l|}
\hline Journal: & Journal of Engineering Design \\
\hline Manuscript ID: & Draft \\
\hline Manuscript Type: & Article \\
\hline Keywords: & $\begin{array}{l}\text { inclusive design, usability, human factors < Design Methods, } \\
\text { Techniques and Tools, user evaluation < Design Theory and } \\
\text { Research Methodology, digital programmable thermostats }\end{array}$ \\
\hline
\end{tabular}

\section{SCHOLARONE ${ }^{\text {m }}$ Manuscripts}




\title{
An investigation into usability and exclusivity issues of digital programmable thermostats
}

\begin{abstract}
With nearly $60 \%$ of domestic energy consumption relating to space heating the interaction between users and their heating controls is crucial in reducing this consumption. Yet many heating controls are complex and exclude people due to the demands placed upon their capabilities in terms of vision, reach, dexterity and thinking. This study explores the scale of and reasons for user exclusion in relation to digital programmable thermostats. The Exclusion Calculator was used to estimate the percentage of the population excluded from use of the three products. Full user testing was then conducted to elicit specific usability problems of the devices. The participants were a group of fourteen younger users (aged 24-44) and ten older users (aged 62-75). The exclusion calculations underestimated the actual exclusion significantly for both age ranges. None of the older users were able to complete the task. In addition the cognitive demands of these systems are considered using mental workload assessment and these were found to be excessive. In conclusion, the study makes recommendations to facilitate the design of more inclusive digital programmable thermostats. It is argued that implementing such changes could results in reductions in domestic heating consumption.
\end{abstract}

Keywords: inclusive design; usability; human factors; user evaluation; digital programmable thermostats

\section{Introduction}

If the UK is to meet its target of an $80 \%$ reduction in carbon dioxide $\left(\mathrm{CO}_{2}\right)$ emissions on 1990's levels by 2050 then substantial decreases in emissions from residential buildings are required. In 2008 residential buildings were responsible for approximately $149 \mathrm{MtCO}_{2}$ emissions (Committee on Climate Change 2008), which equates to $27 \%$ of the UK's $\mathrm{CO}_{2}$ emissions (Boardman 2007). These emissions are primarily due to space heating, accounting for nearly $60 \%$, with average internal temperatures steadily increasing from $13^{\circ} \mathrm{C}$ in 1970 to $18^{\circ} \mathrm{C}$ in 2000 (Department of Trade and Industry 2008). The Committee Climate Change estimates that $5.5 \mathrm{MtCO}_{2}$ could be saved by turning down domestic thermostats by just $1{ }^{\circ} \mathrm{C}$ with minimal impact on comfort (Committee on Climate Change 2008). 
Despite the technology existing to optimise domestic heating settings and reduce energy consumption controls are not used effectively. Simpler control systems could have multiple benefits including reduced energy consumption, greater thermal comfort and a greater understanding of the system (Bordass, Leaman 2001). An earlier study found the $66 \%$ of users at a low-carbon housing development could not program their controls as desired due to the complexity of the system (Combe et al. 2010). Gupta, Intille \& Larson (2009) state when programmed effectively controls can save substantial amounts of energy, yet there is little evidence that this is the reality (Gupta, Intille \& Larson 2009). This study investigates the reasons why users, older users in particular, have difficulties using heating controls effectively.

Several recent studies have developed solutions that aim to reduce domestic heating consumption however these have not addressed usability issues specifically. Caird \& Roy (2008) argue that the lack of engagement with heating controls can partially be attributed to insufficient consideration of user requirements and product usability (Caird, Roy 2008). Crucially, in terms of usability, older people were found to struggle with the visual requirements of small buttons and displays. Both studies by Zhang, Rau \& Salvendy (2009) and Sauer, Wastell \& Schmeink (2009) acknowledge issues older users may have with interfaces. When using a smart home interface to control a range of energy consuming activities within the home, older users took longer to complete tasks and made more errors than younger users (Zhang, Rau \& Salvendy 2009).

The study by Sauer, Wastell \& Schmeink (2009) focuses on the information provided by the interface. They hypothesised that providing more advanced support for users may result in benefits, such as reduced energy consumption. Their results showed that the predictive display led to improved ecological performance over any 
other display types and helped lower working memory load by reducing the need to plan in advance (Sauer, Wastel \& Schmeink 2009). Although improved usability was not a primary concern in their study it was recognised that older users may experience usability problems with the system and improvements in this area could produce additional energy savings.

By designing controls inclusively so that pro-environmental behaviour is easily accomplished considerable energy savings could be made. Inclusive design is a people-centred design approach that places users at the core of its processes. It aims to consider the needs of the widest range of possible users in the design of a product or system (Keates, Clarkson 2003). However, it recognises that it is not possible for one particular design solution to satisfy the needs of all users.

Despite a range of barriers being identified as to the uptake of inclusive design methods (discussed in the work of (Dong 2004) many companies are still failing to implement inclusive design in practice (Goodman-Deane, Langdon \& Clarkson 2010). User involvement in the design process is seen as the ideal within the inclusive design community however this is not always practical, primarily due to time and budget constraints (Goodman-Deane, Langdon \& Clarkson 2010, Cardoso, Clarkson 2010).

Goodman-Deane, Langdon \& Clarkson (2010) found a tendency for designers to employ "informal, low-cost ways of considering users". One such way is the Exclusion Calculator developed by the Engineering Design Centre at the University of Cambridge. It is used to estimate the number of users excluded by a product or service due to the capability demands required and a full explanation of the Exclusion Calculation can be found in (Waller, Langdon \& Clarkson 2009). 
This study uses the Exclusion Calculator as a point of comparison between the estimated exclusion and the actual exclusion found through usability testing. This has been conducted for three types of heating controllers and aims to better understand the cognitive reasons for user exclusion with these types of products. By establishing these issues for both older and younger users a more inclusive solution can be designed. The main hypothesis of this research is that energy savings could be made as a direct result of designing an inclusive heating control system.

\section{Methods}

\subsection{Participants}

The participants were 14 self selected people working with the Buro Happold London Office, and 10 from the Brunel Older People's Reference Group. The group from Buro Happold were aged between 24 and $44($ mean $=28.7$ years, male $=8$, female $=$ 6) whilst the participants at Brunel were between 62 and 75 years old (mean $=69.6$ years, male $=5$, female $=5$ )

The number of participants in usability testing is recommended to be no less than ten users (Nielsen 1993). Yet Wickens et al. (2004) argue that although when using more than six to eight users identified the value of the information gathered diminishes. The study was approved by the Brunel University Ethics Committee and after a thorough explanation participants were asked to sign an informed consent form.

\subsection{Task}

Both groups of participants were given the scenario to set a heating controller to heat the home during specified hours. These instructions were detailed in written and tabular format and the participants had the opportunity to ask for clarification of the 
instructions. The settings used in the task are detailed in Table 1 and at any other occasion the temperature was to be left at the default setting. No further help was provided by the researcher during the task.

\begin{tabular}{|l|l|l|}
\hline Day & Time & Temperature \\
\hline Monday-Friday & $7 \mathrm{am}-9 \mathrm{am}$ & $19^{\circ} \mathrm{C}$ \\
\hline & $4 \mathrm{pm}-11 \mathrm{pm}$ & $21^{\circ} \mathrm{C}$ \\
\hline Saturday \& Sunday & $7 \mathrm{am}-9 \mathrm{am}$ & $19^{\circ} \mathrm{C}$ \\
\hline & $6 \mathrm{pm}-10.30 \mathrm{pm}$ & $21^{\circ} \mathrm{C}$ \\
\hline
\end{tabular}

Table 1. Settings used in the usability testing

\subsection{Equipment/Selection of Devices}

Digital programmable thermostats are one of a wide range of heating controls available to users offering control over both temperature and duration of heating. Figure 1 illustrates the range of controls available to the user and the context of programmable thermostats in the market place. The decision to focus on digital programmable thermostats is consistent with the industry move from manual to digital interfaces.

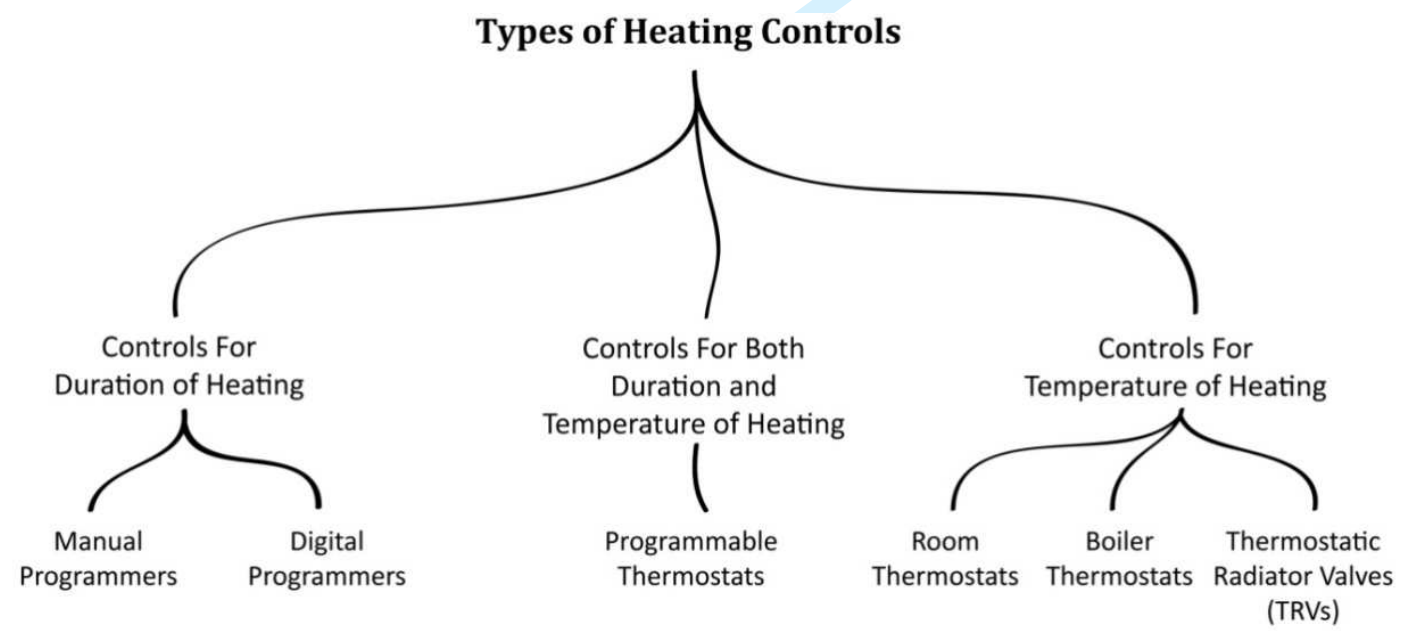

Figure 1. Types of Heating Control

The controls selected for the study, all digital programmable thermostats, were the Honeywell CMT927, Siemens REV24-RF and Drayton Digistat+3 which have similar functionality presented in three individual manners. The Honeywell 
control works on an individual day basis whereas the Drayton and Siemens controls allow programming blocks of days. The Siemens control works on a slider concept which is unique and requires a large amount of dexterity. The Drayton control provided the same functionality as the other controls through only four buttons labelled plus, minus, left arrow and right arrow.

All of the selected controls allow programming for both the weekdays and weekends with six programming time periods per day. Two of the products (Honeywell and Drayton) are listed as recommended products on the Energy Savings Trust website whereas an older model of the Siemens control, the REV23RF, is listed.

\subsection{Procedure}

The study began with a paper based survey to gather background data and assess prior usage of digital thermostats, computers and mobile phones. Participants were then asked to perform the task, which was observed and timed, to assess the ease of learning of the interface and level of instruction use. Exclusion calculations were conducted prior to the usability testing for comparison with the task performance results. Lastly mental workload (MWL) was assessed using the NASA Task Load Index (NASA TLX; Hart \& Staveland, 1988 cited in (Stanton et al. 2005).

\subsubsection{Exclusion Calculations}

The Exclusion Calculator is a publicly available tool (http://www.inclusivedesigntoolkit.com) used to estimate the number of people currently excluded by a product by considering how demanding each task is using a scale from low to high (Goodman, Waller 2007). Each control was assessed prior to the usability testing to indicate which capabilities would be most demanding and estimate the percentage of users who would not be able to complete the task. 
The capabilities assessed in the calculation are vision, hearing, dexterity, thinking, locomotion and reach \& stretch. User capability is defined as "an individual's level of functioning, along a given dimension from very high ability to extreme impairment, which has implications for the extent to which they can interact with products" (Johnson, Clarkson \& Huppert 2010).

The level of demand required is then correlated to the number of people who would find the task impossible giving an overall percentage of the population excluded. This data comes from the Disability Follow-up Survey by Grundy et al (1999), as it is the best suited data for use in inclusive design (Johnson, Clarkson \& Huppert 2010, Grundy et al. 1999).

However, data upon which the Exclusion Calculator is based is seen as insufficient to estimate cognitive capabilities accurately, as they are particularly difficult to illicit from users (Cardoso, Clarkson 2010). Therefore direct user involvement is required when trying to understand the cognitive demands of a product or system and hence the combination of methods in this study. The calculations were conducted for the population as a whole and specifically for the older age group of the participants. It serves as a useful comparison with the direct user testing completed subsequently.

\subsubsection{Usability Testing}

Usability is a key attribute of any interface or system which aims to assess how easy it is for a user to achieve their goal. Neilsen (1993) strongly recommends user based testing as "testing with real users is the most fundamental usability method and is in some ways irreplaceable". The metrics evaluated in this study were participant task performance, time taken and use of instructions. 
The time taken for the user to either complete the task or ask for the instructions was measured using a stop watch. Once the instructions were provided the time the user engaged with the instruction manual was also measured. Success with the task and use of instructions was noted for each user. Furthermore the researcher observed the task to determine where errors occurred in the programming process and the process was audio recorded to capture user comments.

\subsubsection{Mental Workload}

Measurement of mental workload can contribute to the overall assessment of usability and can be measured by task related, subjective measurements or physiological measurements (Stanton et al. 2005, Wickens et al. 2004). This study uses a subjective rating scale rather than task related or physiological measures which were seen as too intrusive for the task and user respectively.

NASA TLX is a multi-dimensional subjective rating measurement that is applied post-task as not to infer with task performance and has been widely validated (Stanton et al. 2005). Users were asked to complete the ratings scales directly after completing the task with each controller. Only the ratings scales section of the NASA TLX was used as (Hendy, Hamilton \& Landry 1993) conclude it is sufficient for producing an estimate of overall workload.

\subsection{Variables}

The user's ability to complete the task may have been influenced by prior experience with a digital programmable thermostat; this was assessed in the questionnaire before attempting the task. It found five younger users and six older users did have a digital programmable thermostat at home. However of these eleven people four admitted they were not the primary user of the controls within the home. 
Participants also detailed their prior experience and current usage of computers and mobile telephones. In terms of computer usage all younger users and $70 \%$ of the older users used a computer on a daily basis. Mobile phone usage varied more. Again all younger users used a mobile phone on a daily basis to make phone calls and send text messages. This compared to $80 \%$ of older users who had a mobile phone with only using one used it on a daily basis to make phone calls and send text messages. This technical experience may have contributed to the younger user's success in the task.

To minimise learning effects and bias of results the order which users received the controls was varied. The controls were reset to the default programme for each user and the current date and time were preset to the correct values. Testing was held in two meeting rooms artificially lit, with a light level of between 370lux and 450lux thus exceeding the recommendations of (British Standards Institute 2009).

\section{Results}

The outcomes of the study are presented in the order in which they were assessed. Firstly the Exclusion Calculation results are presented and the most demanding capabilities highlighted. Secondly, task performance is discussed in terms of performance times, success and instruction use. Lastly insights regarding the mental workload placed upon the user are described.

\subsection{User Exclusion Results}

Prior to commencing the usability testing Exclusion Calculations were conducted on each set of controls. This exclusion is solely for the programming task, which requires no hearing or locomotion capabilities. The calculations were performed for two age 
ranges 16-102 years old (the maximum available data) and 60-80 years old (to represent the older users).

The Drayton control was seen as the least exclusive of the three controls excluding $7.5 \%$ of the population aged $16-102$ and $13.5 \%$ of people ages $60-80$ years old. This is because there is no door to open and only four buttons available to the user. As a result the thinking capability is the most exclusive for these controls followed by the visual demand.

For the Honeywell controls the results was an overall exclusion of $8.25 \%$, this increased for the older user group to $15.5 \%$. The thinking capability was the most exclusive capability for the Honeywell controls, followed by the visual demand.

The Siemens control was viewed as the most exclusive of the three controls excluding $9.5 \%$ of the population aged $16-102$ and $18.2 \%$ of people ages $60-80$ years old. In contrast to the Honeywell and Drayton controls the most exclusive capability for the Siemens control is dexterity due to the high demands of the slider, followed by the cognitive demands.

\begin{tabular}{|l|l|l|}
\hline $\begin{array}{l}\text { Control } \\
\text { Type }\end{array}$ & $\begin{array}{l}\text { \%age of } \\
\text { population } \\
\text { excluded } \\
\text { aged 16-102 }\end{array}$ & $\begin{array}{l}\text { \%age of } \\
\text { populatio } \\
\mathrm{n} \\
\text { excluded } \\
\text { aged 60- } \\
80\end{array}$ \\
\hline Drayton & $7.5 \%$ & $13.5 \%$ \\
\hline Honeywell & $8.25 \%$ & $15.5 \%$ \\
\hline Siemens & $9.5 \%$ & $18.2 \%$ \\
\hline
\end{tabular}

Table 2. Exclusion Calculation Results 


\subsection{Task Performance Results}

Older users found the task complex and frustrating on the whole. None of the older users completed the task successfully with any of the controls. Despite this it was clear that the Honeywell interface provided greater affordances to the users as only two requested the instructions. The Drayton interface was challenging for the older users; $80 \%$ required the instructions and the average time spent using them was over ten minutes. The time spent for both user groups with and without the instructions is shown in Figure 2. These times are irrelevant of task success due to the fact none of the older users were successful.

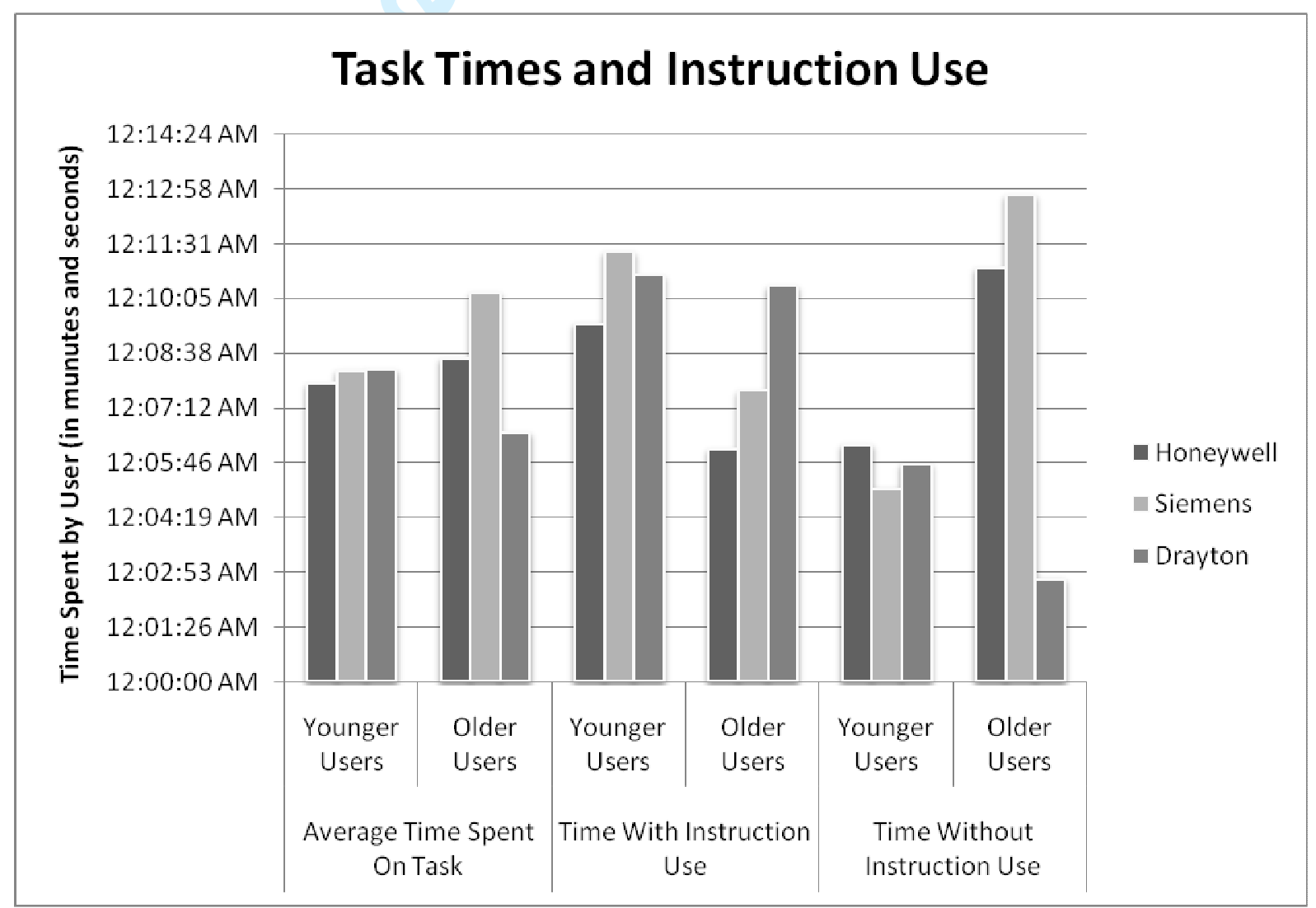

Figure 2. Time spent attempting the task for both user groups

The Siemens control was most difficult for the older users to interact with.

Only one user did not request the instructions whilst attempting the task with the

Siemens control. Many of the older users did not see the door and several could not 
find the slider for long periods of time, if at all. Four of the nine users who requested the instructions were too intimidated to even attempt the task due to the volume of information and the number of symbols.

Younger users had greater success with the task in comparison. The number of younger users successful in completing the task for each control is detailed in Figure

3. Again the use of the Honeywell control performed well without the instructions with 9 of the users being successful (overall 10 users were successful).

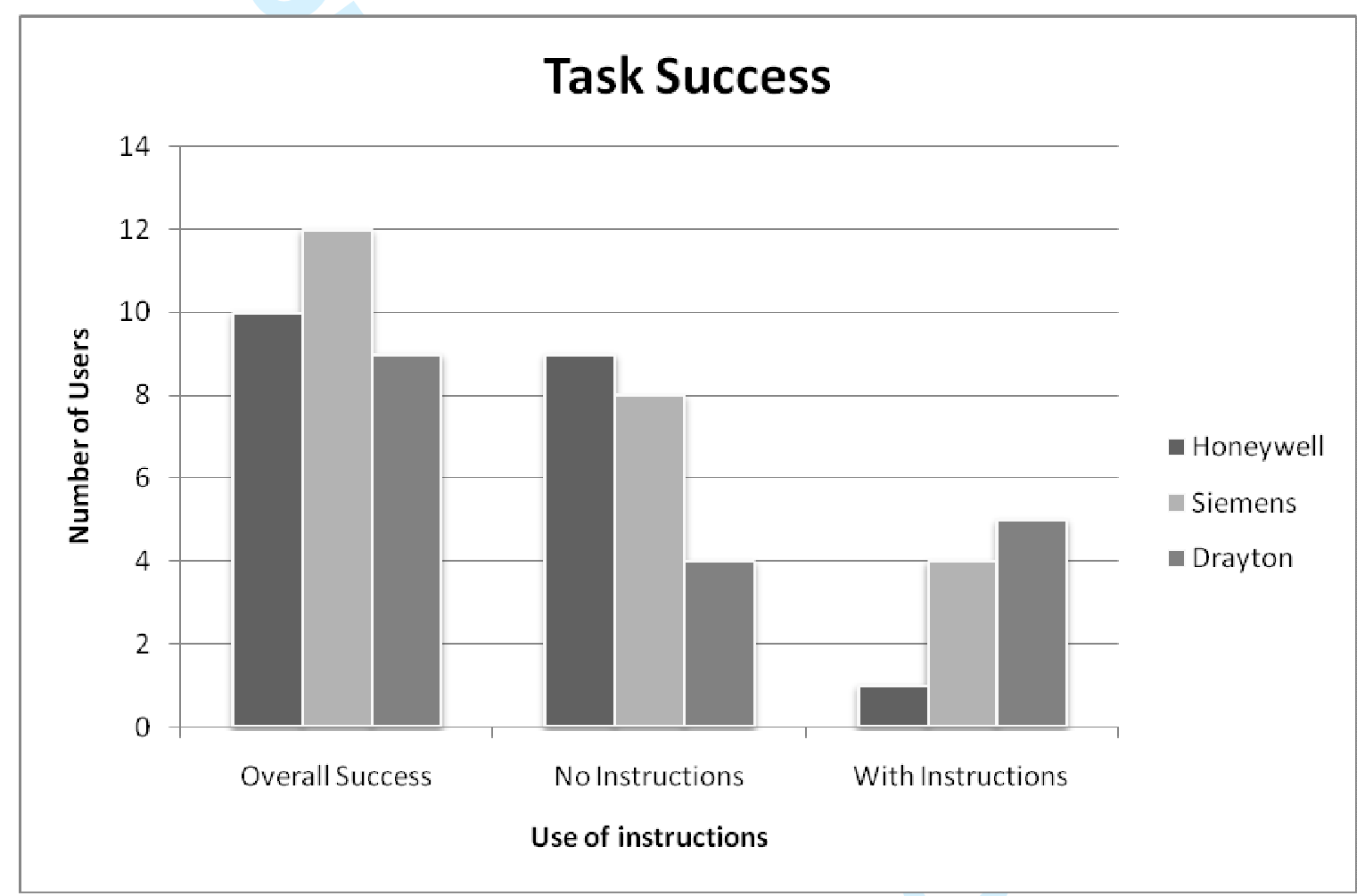

Figure 3. Task success for the younger user group

In contrast to the older users the younger users were most successful with the Siemens control; 12 out of 14 of younger users were successful, 8 without the use of the instructions. The Drayton control is the only one of the three controls tested which the younger users spent longer than the older users both with and without the instructions. This is partly to do with the length of time the task took to complete successfully. However of the younger users 5 were not successful in completing the 
task; the highest failure rate amongst the younger users. Use of instructions for each control for both user groups is illustrated in Figure 4.

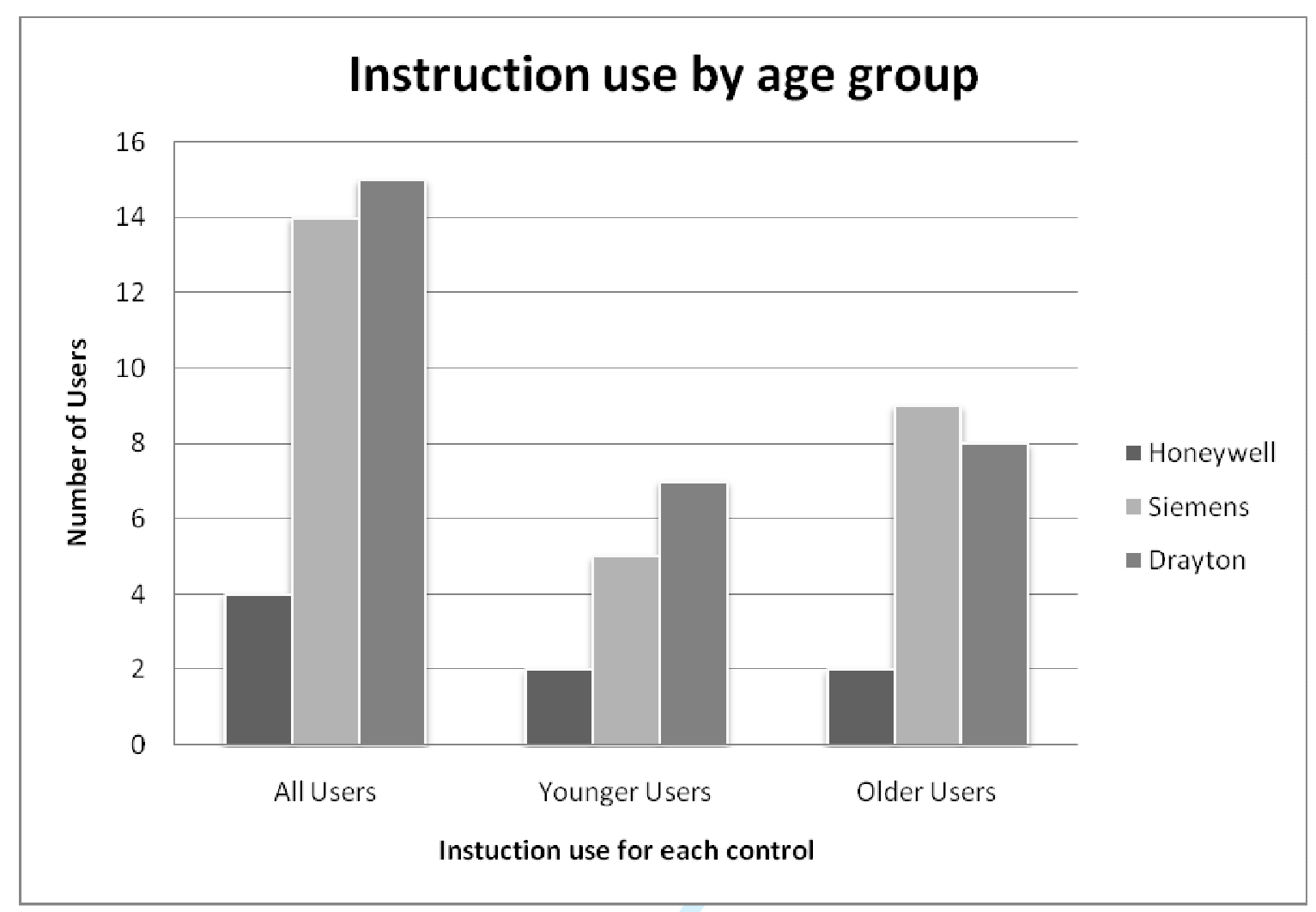

Figure 4. Use of instructions in attempting the task for both user groups

\subsection{Estimated exclusion versus actual exclusion}

The Exclusion Calculation result s and the task success results have been compared in

Figure 5 to make the difference between the two sets of results explicit. It has been assumed if a user was unable complete the task successfully then they have been excluded. Such a vast difference between the estimated and actual exclusions underlines the need to involve users directly in the design process wherever possible. The trend of the estimated exclusion increasing with age has been verified, yet complete exclusion of the older users was not expected. 


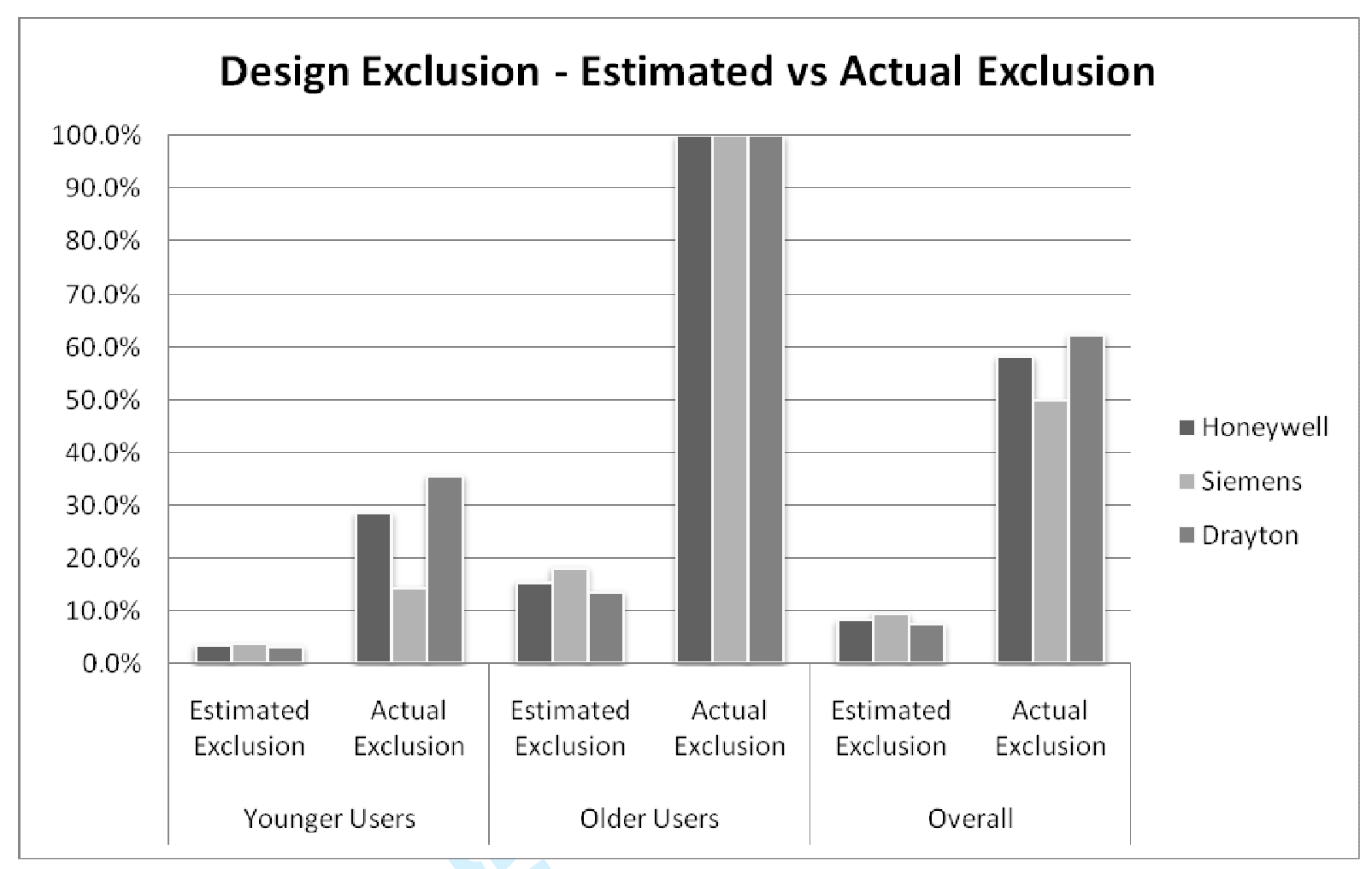

Figure 5. Estimated user exclusion versus actual user exclusion

\subsection{Mental Workload Assessment}

Overall the mental workload ratings confirmed that users found the cognitive elements of the task demanding with an average rating $65.7 \%$ for mental demand, second only to the average frustration level of $66.0 \%$.

The mental workload associated with the Honeywell controls was the least demanding overall, with an average workload of 51.3\% shown in Figure 5. This was consistent for both the older and younger user groups. Younger users were most successful in using the Honeywell controls and consequently rated their performance well. The performance rating on the scales is reversed so a high score means a low perceived performance and thus an increased mental workload. In comparison older users rated their performance poorly despite engaging with the controls for longer and without the need for instructions. 


\section{Honeywell Mental Workload}

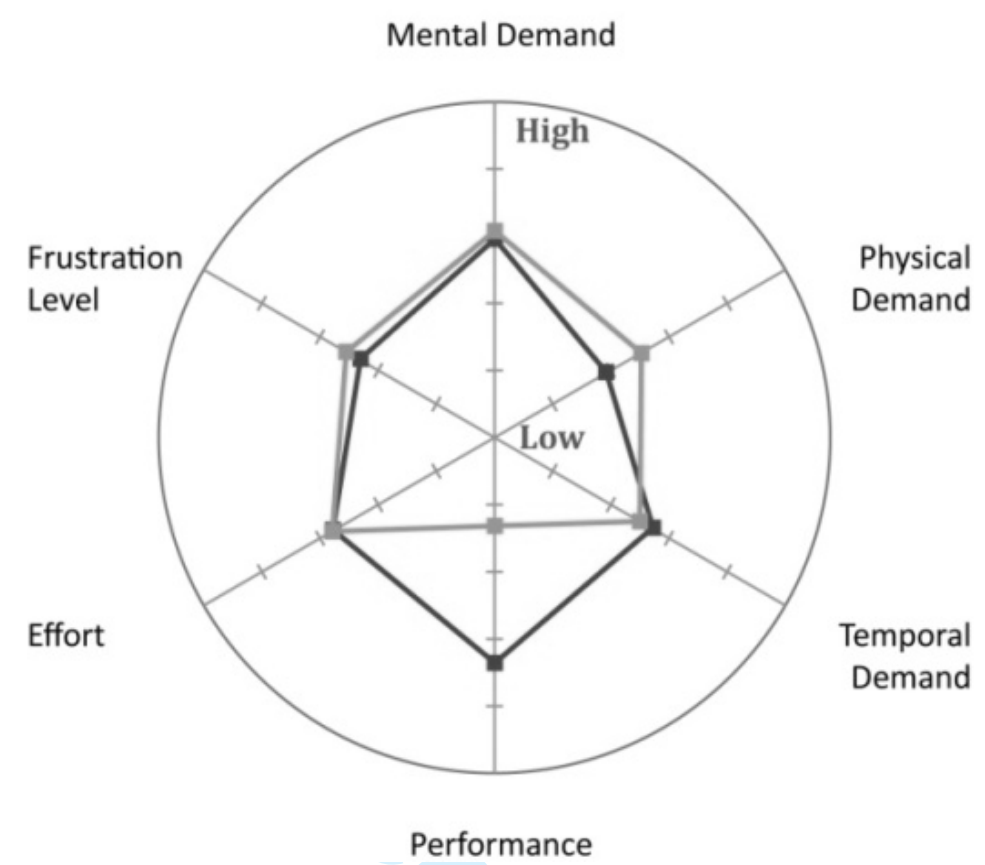

Figure 6. Mental Work Load of the Honeywell Controls

The Siemens control was perceived to have the most challenging mental workload overall averaging $65.8 \%$, shown in Figure 6 . The slider concept required to use the product did not seem intuitive for the older users, resulting in high levels of effort, frustration, mental demand and a low perception of performance.

\section{Siemens Mental Workload}

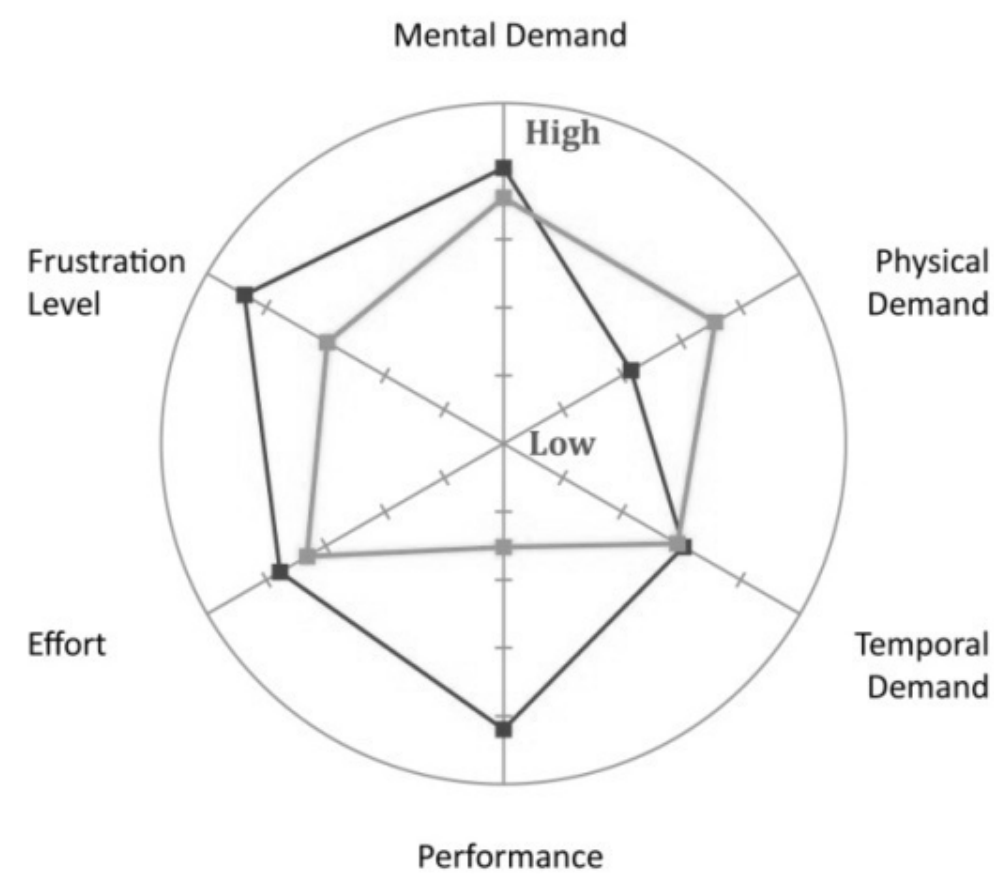


Figure 7. Mental Work Load of the Siemens Controls

The Drayton controls were rated similarly high by both user groups, shown in Figure 7 , with an average mental workload of $62.7 \%$. Notably the older users were more satisfied with their performance using the Drayton control than the Siemens control whereas the young users rate their perceived performance with the Drayton worst of all. Furthermore the workload associated with using the Drayton controls was similar for both user groups with frustration highest for this control averaging $76.3 \%$.

\section{Drayton Mental Workload}

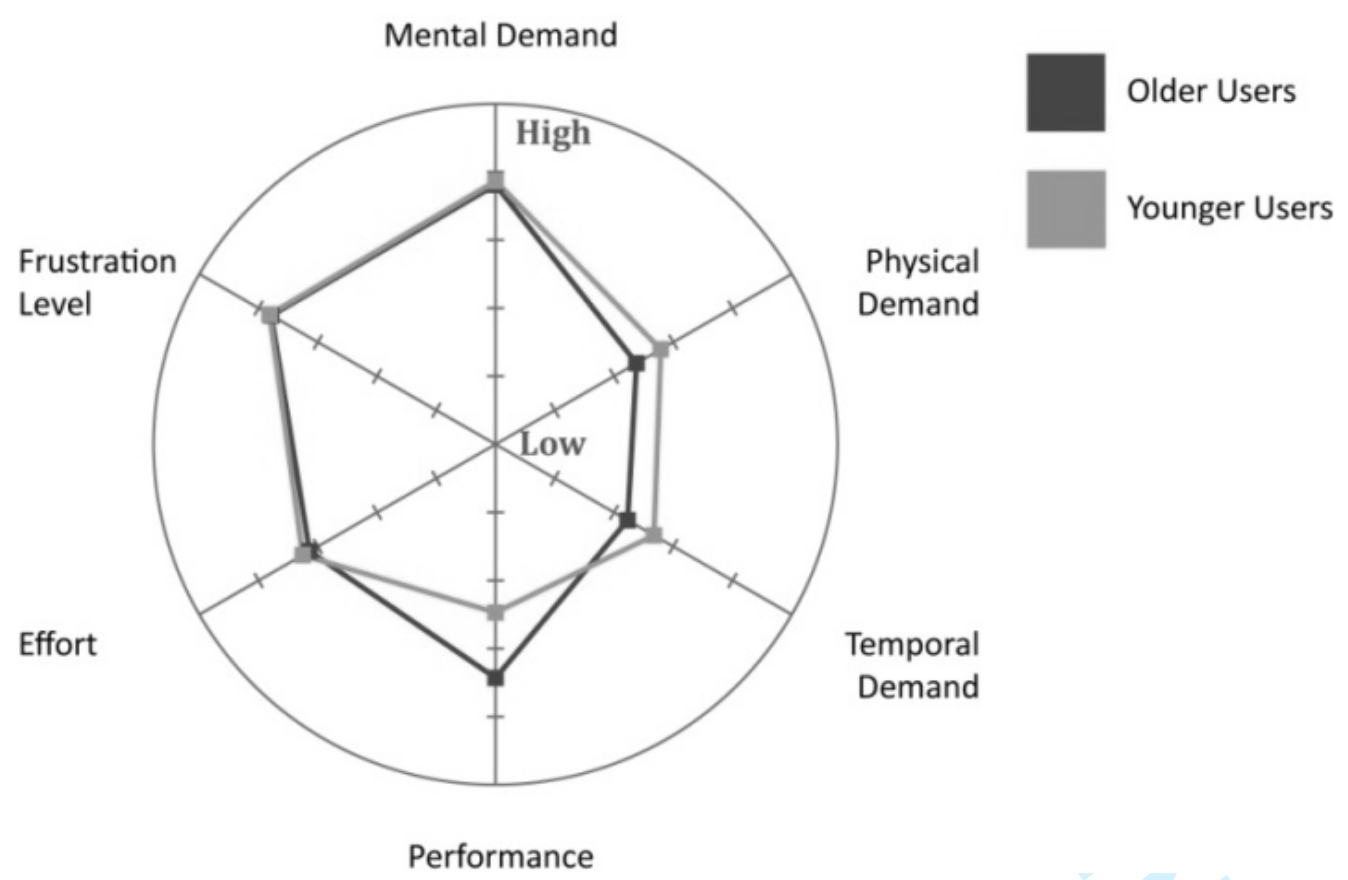

Figure 8. Mental Work Load of the Drayton Controls

\section{Discussion}

\subsection{User Observations}

Observing the task proved invaluable in establishing where users experienced difficulties. The fact that only four of the twenty four users asked for the instructions for the Honeywell controls is encouraging. This indicates that the interface supported 
the user enough for them to make a substantial attempt at the task. The provision of an "OK" button gave users confidence that they had completed an action and the feedback from the interface was useful to users.

Although the Honeywell interface did support the user with well labelled buttons the abundance of buttons proved a distraction to users. In particular this was true for buttons such as Party, Holiday and Exception Day modes. One older user commented "I can't think what they, what these buttons would be, they don't seem to mean a lot to me" in reference to these buttons. While another commented that on the interface "there is too much to read and there are too many little things". This was not limited to the older users with the younger users also commenting "oh my goodness what do all these do?" "What the hell are these? Holiday setting, evening setting..." and "the champagne icon what the hell is that?"

The main source of user error was that users did not understand the concept of time periods. The Honeywell control provides six intervals which can be programmed individually. Five of the users did not understand that the second, fourth and sixth time periods are essentially the finish or off times and did not turn the temperature down at this point. This resulted in users heating through the day at $19^{\circ} \mathrm{C}$ and through the night to $21^{\circ} \mathrm{C}$. In reality this would result in unwanted and unnecessary energy consumption.

The main usability problems with regard to the Siemens controls were that users did not initially understand there was a door and could not find the slider as there is no indication or labelling of it on the interface. One of the younger users and three of the older participants had the door opened by the researcher upon asking for the instructions. Half of the older users failed to identify where the slider was. Two participants commented "It refers to a slider but I can't see how to adjust the slider" 
and "I haven't even figured out which is the slider" implying they were aware they required to use a slider.

Upon opening the door and seeing the interface and symbols displayed on it two younger users exclaimed "Oh wow!" and "you're joking!" indicating their intimidation. Similarly older users exclaimed "Oh heavens!", "Nope doesn't mean anything to me" and "I don't think I like this". The user's reaction to the instructions was predominantly negative with younger users remarking "so the instructions are pretty rubbish" and "actually the instructions just confused me". The older user group also had difficulty with the instructions saying "You'd need a full day for this. Good thing I haven't got these at home!", “I wouldn't even attempt it because that is, this is an instruction nightmare" and "I wouldn't even bother! Those instructions are horrible." One older participant who found the instructions particularly complex said:

"This to me is just crazy. You start to read this, there is so much, it's small, you're peering at it, the symbols are covered in lines, it's extremely small you trying to work out what all the symbols mean. By the time I've got done to number 8 I've forgotten what the first six are. I would find that impossible to set up."

In completing the task the main point of difficulty and confusion in the process was idea of a "comfort pattern" (similar to the time periods concept of the other controls). This function allowed the user to select how many phases the heating will be active for in one day. This proved a problem because if the user did not engage with this function they were unable to set the evening settings on the weekend, which had a default of one phase (i.e. continuous heating all day). When the users tried to set the evening times and temperatures "Pass" was displayed to their confusion. This resulted in fatal errors in the task for the two younger users who were unsuccessful and the one older user who did not use the instructions. 
Usability problems observed when users attempted the task using the Drayton controls included the interface only having four buttons. When attempting the task $60 \%$ of the older users and $64.3 \%$ of younger users looked for more controls. Several removed the battery cover to see if there were further controls available. This occurred even when the control was the first used with younger users commenting "Four buttons only!", "Wow it doesn't open?" "Are these all the buttons?" and "Is that all there is to it? Wow, not much".

The minimal use of buttons meant that no Confirm, Enter or Ok was available to users. This caused frustration for both user groups and three users developed coping strategies by trying to press two buttons together as an enter function. This is a feature that users would have appreciated and felt was lacking commenting "Doesn't seem to be an enter mode on it, you know? That would help" and "Wow is there not like a confirm button or something?".

Frustration with the programming task occurred when users were trying to change the time and the control went through each minute making the process particularly time consuming. Frequent complaints were heard from users including "this is slow", “This takes forever. Right. Oh ... Go up!” and "Can you not do the time quicker?" This was a fatal error in the programming process for one older user who said:

"this is going to take a long time because it takes a long time to adjust the time because you have to press every minute. So I think I would probably get to do this in the end but I'm not going to sit here and waste your time any longer"

When users attempted to set the third time period to the evening time it would stop at 13:59 as time period four was set to 14:00 by default. It would not let users bypass periods three and four automatically (which the Honeywell control did allow) and users were forced to use all six time periods. One younger user commented "I was 
fairly confident that I knew what I was doing there until the times getting stuck. I don't know why".

\subsection{Study Limitations}

The complete failure of the older user groups to complete the task could be due to the complexity of the task itself. Measures were taken to ensure the task was clearly explained in writing with a summary table of numeric values and the researcher available to answer questions relating to the task. Time was provided for the users to read and clarify the task before attempting with the first control. Instead of utilising the full capabilities of the controls only two heating phases were requested rather than the three available. For consistency the morning heating phase had the same temperature for both the weekdays and the weekends, as did the evening heating phase. The time period for the morning heating phase was also kept the same for further consistency.

Due to the small study sample the success rates cannot be extrapolated for the whole population. The exclusion calculations clearly highlighted that the cognitive element of using the product was the main area of exclusion. However, the results of the exclusion calculations underestimated the number of users that could not complete the task significantly.

The study is also limited by the fact that only three products were assessed.

This was to ensure the participants were not put under undue stress and the testing did not induce fatigue. There are a large range of products available however the functionality of the controls was felt to be representative of the wider market. 


\subsection{Design Recommendations}

The study has lead to several design recommendations to help support the effective use of controls by users. These recommendations are:

- Provide clear on and off times (rather than time periods or comfort phases) to avoid unintentional and unnecessary periods of heating

- Greater feedback provided to the user including a summary of settings

- Clear instructions to support the user

- Standardisation of symbols across interfaces

- A Confirm, Enter or Ok button should available to users to save the settings programmed

Implementing these recommendations would reduce the cognitive load placed on the user and could enable effective use of the controls.

\section{Conclusions}

This study indicates that all users experienced severe difficulties in programming the heating controls; these difficulties were especially prevalent in the older user group. An excessive mental workload was placed upon both user groups by the controls, with mental demand and frustration being rated highly for all three. As a direct consequence many users indicated they would not use these products through choice and it is this negative reaction which reduces the potential to heat the home efficiently.

Moreover, this feeling of dissatisfaction and intimidation amongst users was clearly apparent when using the manufacturer's instructions. The Siemens' instruction manual was particularly off-putting with four of the ten older users being too intimidated by the instructions to even attempt the task. Only three of the users 
managed to complete the task successfully without requiring instructions for any of the controls. The interface should provide the users with the necessary affordances to enable them to use the product as is intended.

The main cognitive issue for users appears to be the idea of time periods rather than an on/off time. This resulted in controls being unintentionally programmed to heat throughout the day and night. If this part of the process was made explicitly clear undoubtedly energy savings could be made. In addition providing a summary of the settings may alert users to any mistakes they may have made and avoid periods of unintended heating. Overall there was a lack of system transparency and feedback to the users.

Despite the small sample size the study emphasises the importance of directly involving users in the design process. The Exclusion Calculator provided valuable insight at the start of the process, making explicit where design exclusion was likely to occur. However these results did not reflect the exclusion found through usability testing. Furthermore the limited sample size means the findings cannot be generalised for the wider population.

Although the study is limited to three digital programmable thermostats the results are a useful contribution to the design of future heating control systems. The study shows that both user groups had difficulties with the task and these problems were exacerbated amongst the older users. Improving the usability of these controls will undoubtedly help their effective use and in turn potentially reduce domestic energy consumption. One key aspect of future research remains measuring the scale of the energy savings achievable through improved user interface design. 
Acknowledgements - The authors gratefully acknowledge the participants from both user groups for giving up their time and providing such useful comments on their experience whilst using the heating controls. Without their cooperation, in sometimes frustrating circumstances, the study would not have been possible. Furthermore the authors would like to thank the ESPRC and Buro Happold for funding this research.

\section{References}

Boardman, B. 2007, Home Truths: A Low Carbon Strategy To Reduce UK Housing Emissions by $80 \%$ by 2050 , Environmental Change Institute; University of Oxford, Oxford.

Bordass, B. \& Leaman, A. 2001, "Assessing building performance in use 4: the Probe occupant surveys and their implications", Building Research and Information, vol. 29, no. 2, pp. 129-143.

British Standards Institute 2009, BS 8300:2009 Design of buildings and their approaches to meet the needs of disabled people - Code of Practice, British Standards Institute, Chiswick, UK.

Caird, S. \& Roy, R. 2008, "User-Centred Improvements to Energy Efficiency Products and Renewable Energy Systems: Research on Household Adoption and Use", International Journal of Innovation Management, vol. 12, no. 3, pp. 327-355.

Cardoso, C. \& Clarkson, J. 2010, "Simulation in user-centred design: helping designers to empathise with atypical users", Journal of Engineering Design, vol. iFirst, pp. 1-22.

Combe, N., Harrison, D., Dong, H., Craig, S. \& Gill, Z. 2010, "Assessing the number of users who are excluded by domestic heating controls", International Journal of Sustainable Engineering, vol. accepted 4th May 2010, no. In press.

Committee on Climate Change 2008, Building a Low Carbon Economy - The UK's contribution to tackling climate change, The Stationery Office, Norwich.

Department of Trade and Industry 2008, Energy Consumption in the United Kingdom, Office of National Statistics, London.

Dong, H. 2004, Barriers to Inclusive Design in the UK: A Thesis Submitted for the Degree of Doctor of Philosophy, Department of Engineering, University of Cambridge, Cambridge, UK.

Goodman, J. \& Waller, S. 2007, "Evaluation Tools" in Inclusive Design Toolkit, eds. J. Clarkson, R. Coleman, I. Hosking \& S. Waller, Engineering Design Centre, University Of Cambridge, Cambridge, pp. 3-42 - 3-62.

Goodman-Deane, J., Langdon, P. \& Clarkson, J. 2010, "Key influences on the usercentred design process", Journal of Engineering Design, vol. 21, no. 2-3, pp. 345-373.

Grundy, E., Ahlburg, D., Ali, M., Breeze, E. \& Sloggett, A. 1999, Disability in Great Britain: Results from the 1996/97 Disability Follow-up to the Family Resources Survey, Department of Social Security, Leeds.

Gupta, M., Intille, S.S. \& Larson, K. 2009, "Adding GPS-Control to Traditional Theromstats: An Exploration of Potential Energy Savings and Design Challenges", Pervasive Computing, Lecture Notes in Computer Science, vol. 5538, pp. 95-114. 
Hendy, K.C., Hamilton, K.M. \& Landry, L.N. 1993, "Measuring Subjective Workload: When is one scale better than many?", Human Factors, vol. 35, no. 4, pp. 579-601.

Johnson, D., Clarkson, J. \& Huppert, F. 2010, "Capability measurement for Inclusive Design", Journal of Engineering Design, vol. 21, no. 2-3, pp. 275-288.

Keates, S. \& Clarkson, J. 2003, Countering Design Exclusion: An Introduction to Inclusive Design, Springer, London.

Nielsen, J. 1993, Usability Engineering, 1st Edition edn, AP Professional, Cambridge, Massachusetts.

Sauer, J., Wastel, D.G. \& Schmeink, C. 2009, "Designing for the home: A comparative study of support aids for central heating systems", Applied Ergonomics, vol. 40, pp. 165-174.

Stanton, N., Salmon, P.M., Walker, G.H., Baber, C. \& Jenkins, D.P. 2005, Human Factors Methods: A Practical Guide for Engineering and Design, 1st edn, Ashgate, Farnham, Surrey.

Waller, S., Langdon, P. \& Clarkson, J. 2009, "Using disability data to estimate design exclusion", Universal Access in the Information Society, vol. Online First, no. DOI 10.1007/s10209-009-0168-x.

Wickens, C.D., Lee, J., Liu, Y.D. \& Gordon-Becker, S. 2004, An Introduction to Human Factors Engineering, 2nd Edition edn, Pearson Education, London.

Zhang, B., Rau, P.P. \& Salvendy, G. 2009, "Design and evaluation of smart home user interface: effects of age, tasks and intelligence level", Behaviour and Information Technology, vol. 28, no. 3, pp. 239-249. 
Tables

Table 1. Settings used in the usability testing

\begin{tabular}{|l|l|l|}
\hline Day & Time & Temperature \\
\hline Monday-Friday & $7 \mathrm{am}-9 \mathrm{am}$ & $19^{\circ} \mathrm{C}$ \\
\hline & $4 \mathrm{pm}-11 \mathrm{pm}$ & $21^{\circ} \mathrm{C}$ \\
\hline Saturday \& Sunday & $7 \mathrm{am}-9 \mathrm{am}$ & $19^{\circ} \mathrm{C}$ \\
\hline & $6 \mathrm{pm}-10.30 \mathrm{pm}$ & $21^{\circ} \mathrm{C}$ \\
\hline
\end{tabular}


Table 2. Exclusion Calculation Results

\begin{tabular}{|l|l|l|}
\hline $\begin{array}{l}\text { Control } \\
\text { Type }\end{array}$ & $\begin{array}{l}\text { \%age of } \\
\text { population } \\
\text { excluded } \\
\text { aged 16-102 }\end{array}$ & $\begin{array}{l}\text { \%age of } \\
\text { populatio } \\
\mathrm{n} \\
\text { excluded } \\
\text { aged 60- } \\
80\end{array}$ \\
\hline Drayton & $7.5 \%$ & $13.5 \%$ \\
\hline Honeywell & $8.25 \%$ & $15.5 \%$ \\
\hline Siemens & $9.5 \%$ & $18.2 \%$ \\
\hline
\end{tabular}


Figure Caption List

Figure 1. Types of Heating Control

Figure 2. Time spent attempting the task for both user groups

Figure 3. Task success for the younger user group

Figure 4. Use of instructions in attempting the task for both user groups

Figure 5. Estimated user exclusion versus actual user exclusion

Figure 6. Mental Work Load of the Honeywell Controls

Figure 7. Mental Work Load of the Siemens Controls

Figure 8. Mental Work Load of the Drayton Controls 